\title{
EANM position paper on article 56 of the Council Directive 2013/59/Euratom (basic safety standards) for nuclear medicine therapy
}

\author{
Mark Konijnenberg $^{1} \cdot$ Ken Herrmann $^{2} \cdot$ Carsten Kobe $^{3} \cdot$ Frederik Verburg $^{1} \cdot$ Cecilia Hindorf $^{4} \cdot$ Roland Hustinx $^{5}$. \\ Michael Lassmann ${ }^{6}$ (i)
}

Received: 5 June 2020 / Accepted: 11 September 2020 / Published online: 15 October 2020

(C) The Author(s) 2020

\section{Executive Summary}

The EC Directive 2013/59/Euratom states in article 56 that exposures of target volumes in nuclear medicine treatments shall be individually planned and their delivery appropriately verified. The Directive also mentions that medical physics experts should always be appropriately involved in those treatments. Although it is obvious that, in nuclear medicine practice, every nuclear medicine physician and physicist should follow national rules and legislation, the EANM considered it necessary to provide guidance on how to interpret the Directive statements for nuclear medicine treatments.

For this purpose, the EANM proposes to distinguish three levels in compliance to the optimization principle in the directive, inspired by the indication of levels in prescribing, recording and reporting of absorbed doses after radiotherapy defined by the International Commission on Radiation Units and Measurements (ICRU):

- Most nuclear medicine treatments currently applied in Europe are standardized. The minimum requirement for those treatments is ICRU level 1 ("activity-based prescription and patient-averaged dosimetry"), which is defined

This article is part of the Topical Collection on Dosimetry.

Michael Lassmann

lassmann_m@ukw.de

1 Department of Radiology and Nuclear Medicine, Erasmus MC, Rotterdam, Netherlands

2 Department of Nuclear Medicine, University of Duisburg-Essen and German Cancer Consortium (DKTK), University Hospital Essen, Essen, Germany

3 Department of Nuclear Medicine, Faculty of Medicine and University Hospital Cologne, University of Cologne, Cologne, Germany

4 Department of Nuclear Medicine Physics, Skåne University Hospital, Lund, Sweden

5 Service de Médecine Nucléaire et d'Imagerie Oncologique, Département de Physique médicale, Université de Liège GIGA-CRC in vivo imaging, Centre Hospitalier Universitaire de Liège, Liège, Belgium

6 Department of Nuclear Medicine, Universitätsklinikum Würzburg, Klinik und Poliklinik für Nuklearmedizin, Oberdürrbacher Str. 6, 97080, Würzburg, Germany by administering the activity within $10 \%$ of the intended activity, typically according to the package insert or to the respective EANM guidelines, followed by verification of the therapy delivery, if applicable.

- Non-standardized treatments are essentially those in developmental phase or approved radiopharmaceuticals being used off-label with significantly $(>25 \%$ more than in the label) higher activities. These treatments should comply with ICRU level 2 ("activitybased prescription and patient-specific dosimetry"), which implies recording and reporting of the absorbed dose to organs at risk and optionally the absorbed dose to treatment regions.

- The EANM strongly encourages to foster research that eventually leads to treatment planning according to ICRU level 3 ("dosimetry-guided patient-specific prescription and verification"), whenever possible and relevant.

Evidence for superiority of therapy prescription on basis of patient-specific dosimetry has not been obtained. However, the authors believe that a better understanding of therapy dosimetry, i.e. how much and where the energy is delivered, and radiobiology, i.e. radiation-related processes in tissues, are keys to the long-term improvement of our treatments. 
Keywords Nuclear medicine therapy $\cdot$ Dosimetry $\cdot$ Optimization $\cdot$ BSS directive

\section{Introduction}

Personalized therapy was already envisioned by Hippocrates 25 centuries ago: "Let nothing bad be added by the person treating - rather let the evils resulting from the diseases themselves suffice - but only whatever good he is capable of." [1]. Treatments should be optimized for the individual patient between what is tolerable (add nothing bad or side effects) and whatever good is required for efficacy. In radiotherapy, it is an unquestioned paradigm to perform patient-specific treatment planning prior to any course of treatment with external beams or brachytherapy sources.

This optimization principle has been formalized in the EC Directive 2013/59/Euratom, laying down basic safety standards (BSS) for protection against the dangers arising from exposure to ionizing radiation [2], to be valid for all forms of radiotherapy including nuclear medicine therapy. Specifically, article 56 states:

"For all medical exposure of patients for radiotherapeutic purposes, exposures of target volumes shall be individually planned and their delivery appropriately verified taking into account that doses to nontarget volumes and tissues shall be as low as reasonably achievable and consistent with the intended radiotherapeutic purpose of the exposure".

Nuclear medicine therapy is explicitly included by the definition of "radiotherapeutic" to mean pertaining to radiotherapy, including nuclear medicine for therapeutic purposes (condition 81 [2]).

Furthermore, the level of involvement of a medical physics expert is specified in three categories:

(i) In non-standardized therapeutic nuclear medicine practices, a medical physics expert shall be closely involved.

(ii) In standardized therapeutical nuclear medicine practices, a medical physics expert shall be involved.

(iii) For other medical radiological practices, a medical physics expert shall be involved for consultation and advice on matters concerning radiation protection for medical exposure.

The member states had to put into force the laws and regulations necessary to comply with the BSS by at latest 6 February 2018 (cf. Art. 106 of the BSS). Interpretation of the law into practical application is still lacking concerning optimized treatment prescription methods and definitions of standardized and non-standardized therapy. The variations in the practice of nuclear medicine therapies and the related implementation of dosimetry have been explored recently by the EANM internal dosimetry task force [3, 4]. Different approaches to implement the Directive are followed in various European countries, with a good example provided in the consensus document by the Italian nuclear medicine and medical physics associations [5]. Dosimetry-guided treatment is, for most therapeutic compounds, not in line with the instructions for use recommended by European Medicines Agency (EMA), and the posology would need to be modified and complemented in order to comply with the BSS directive. This discrepancy between the optimization principle in the BSS directive and the prescription posology in EMA product approval dossiers for nuclear medicine therapies has been addressed before [6].

\section{Standardized and non-standardized nuclear medicine therapy}

Standardized therapies in nuclear medicine are approved products (by EMA or by CE marking) for radionuclide therapies being administered according to the package inserts or relevant guidelines. Non-standardized therapies are either radionuclide therapies in developmental phase or approved radiopharmaceuticals being used off-label, e.g. by exceeding the maximum allowed activity according to the package insert, also including the total activity administered accumulated over all treatments. The involvement of the medical physics expert (MPE) in standardized therapies entails mostly quality control of the treatment protocol, equipment used and radiation protection responsibility. Recommendations have been formalized by the European Federation of Organizations for Medical Physics (EFOMP) on the involvement of MPEs in radiation therapy; in the practice of standardized therapy, the MPE should monitor this practice regularly and be available on call at all times [7]. We recommend, however, that the MPE is closely involved in the initiation of a new radionuclide therapy for a clinical centre until sufficient routine is gained.

For non-standardized therapies, a medical physics expert should be closely involved meaning to be member of the team that give advice on the therapy for the activity needed (either based on dosimetry or following a fixed activity prescription) and verification of the absorbed doses given in order to avoid acute cases of insufficient dose-coverage or excessive healthy tissue damage. According to the EFOMP [7], an MPE must be present at all times during the entire patient pathway, which does not always seem realistic in clinical practice. However, the MPE does need to be closely involved in the prescription and verification at initial and follow-up non-standardized nuclear medicine therapies. 


\section{Recommendation for levels in compliance to the BSS directive}

Evidence for dose-effect relations after radionuclide therapies is in most cases derived from retrospective studies, which are considered to be at higher risk of potential sources of bias and confounding factors as compared with prospective studies [8], and thus hinders the indisputable application of the optimization principle. Clinical evidence for superiority of prospective therapy prescription on basis of patient-specific dosimetry has not been obtained within nuclear medicine therapy. The EANM proposes therefore to distinguish three levels in compliance to the optimization principle in the BSS directive, following the indication of levels in prescribing, recording and reporting of absorbed doses after radiotherapy defined by the International Commission on Radiation Units and Measurements (ICRU) (see, e.g. ICRU report 91, [9]). These three levels are to be viewed as a staircase where above level 1, levels 2 and 3 add refinements, with purpose to decrease the uncertainty in the absorbed dose estimates for the individual patient. Naturally, compliance to level 2 requires that the demands for level 1 are also met and for level 3 that the demands for both levels 1 and 2 are fulfilled.

\section{Level 1: Activity-based prescription and patient- averaged dosimetry}

Level 1 compliance is the minimum requirement for standardized therapies, and below this level, therapy should not be performed. Level 1 is reached by administering a net activity within $10 \%$ of the intended activity, typically according to the package insert or to the respective EANM or national guidelines. The net activity is defined as the difference of the activity measured before and after administration. The activity metre (or dose calibrator) should be calibrated for measuring the radionuclide used in the therapy relative to a primary standard issued by a national metrology institute, such that traceability is ascertained, and the amount of activity administered can be accurately determined. Qualitative verification of the therapy delivery should be performed at a relevant time point in therapies for which post-therapy imaging is feasible and the results should be recorded. Absorbed dose estimates can be made for patients involved in level 1 therapies by using patient cohort-averaged dosimetry data and the administered activity. There should be sufficient data available for the practitioner to make an informed decision on the efficacy of delivering the treatment at this level, as the absorbed dose to the target volume is not available at level 1.

\section{Level 2: Activity-based prescription and patient- specific dosimetry}

Level 2 compliance is reached by recording and reporting of the absorbed dose to organs at risk and optionally the absorbed dose to treatment regions (regions of disease that motivate treatment prescription) for the individual patient. This level is advised to form the minimum requirement for nonstandardized therapies. If the treatment objective is to avoid toxicity, then the absorbed dose to the organs at risk should be quantified. If the objective is tumour control but also for therapy selection, then the absorbed dose to the treatment region is of relevance. The combined standard uncertainty (one standard deviation) in the relevant absorbed dose is within $20 \%$, depending on the treatment objectives. The activity prescription at level 2 is not different from that in level 1. Level 2 compliance will be useful in deciding on further therapy options at recurrent disease, like external beam radiotherapy or repeating the same therapy as salvage option. Radionuclide therapy in children is highly desired to be given at a level 2 compliance and when possible include optimization to a maximum tolerable absorbed dose in organs at risk (level 3). The organs at risk and treatment regions selected for the calculations need to be those that are most likely to predict biological outcome to assess safety and efficacy of the treatment. Eventually retrospective analysis of the patient-specific dosimetry can lead to an optimized therapy prescription balancing both objectives. The key distinction between level 1 and level 2 is the degree to which the absorbed dose report is patient-specific and also in the degree of its uncertainty. Radiopharmaceuticals in clinical development (phase 1-2 trials) should ideally comply to dose reporting at least at level 2 . Likewise, off-label use with administrations of activity that is significantly higher $(25 \%$ or more) than the recommended activity, including the total activity accumulated over all cycles and treatments, should preferably adhere to level 2 .

\section{Level 3: Dosimetry-guided patient-specific prescrip- tion and verification}

Level 3 compliance is the prescription of administered activity calculated to deliver a desired absorbed dose to a treatment region or organ at risk and is appropriate in a research setting to develop new dosimetry methodologies in order to better predict response or toxicity. For level 3 studies, it is essential that dosimetry and correlations between absorbed dose and induced effects are timely identified and published in peerreviewed literature. These studies may lead to an improved characterization of tumour control and normal tissue complication profiles which could produce more accurate dose-effect relationships. Treatment planning according to a personalized dosimetry would fall within level 3 , and any uncertainty in the absorbed dose estimates should be reported, including possible non-uniformity of the absorbed dose distribution. Reporting of the clinical dosimetry at level 3 should ideally provide a complete overview of the absorbed dose assessment steps enabling reproducibility and expansion of the results [10]. 


\section{Guidance material for treatment and dosimetry protocols}

Several guidance documents have been published on recommended dosimetry procedures for standard radionuclide therapies. Basic standards and nomenclature within dosimetry can be found in the MIRD pamphlets 16, 20, 21 and 22 [11-14], and guidelines for quantitative SPECT are provided in MIRD pamphlets 23, 24 and 26 [15-17]. The EANM dosimetry committee has published standard operating procedures for several radionuclide therapies [18-21], and recommendations for dosimetry of ${ }^{90} \mathrm{Y}$ liver embolization are currently under evaluation. Additionally, recommendations have been written on reporting clinical dosimetry data and a practical guidance on the quantification of the uncertainties associated with dosimetry [10, 22].

Evidence for superiority of therapy prescription on basis of patient-specific dosimetry has not been obtained, although considering ionizing radiation as its mechanism of action absorbed dose is more likely to form a better measure of outcome. A risk analysis model following, e.g. the Failure Mode and Effects Analysis (FMEA) risk model [23], could form a valuable tool to evaluate whether prescription based on fixed activity and patient average dosimetry could lead to serious events or conversely underdosing in a specific patient cohort leading to sub-optimal outcome.

\section{Classification of current nuclear medicine therapies}

Table 1 indicates radionuclide therapies that are classified as standardized and non-standardized, as well as the prescription basis with indication of the appropriate level. Classified as standardized therapies are those that, to date, have marketing authorization by the EMA for the indication stated in the package

Table 1 Classification of radionuclide therapies into standardized and non-standardized modalities with options for prescription and dosimetry, according to the level of compliance to the BSS directive's optimization principle

\begin{tabular}{|c|c|c|c|c|c|}
\hline Disease & $\begin{array}{l}\text { Radionuclide/ } \\
\text { radiopharmaceutical }\end{array}$ & Standardized & Prescription (level) & Dosimetry & Guidance report \\
\hline Benign thyroid disease & {$\left[{ }^{131} \mathrm{I}\right] \mathrm{NaI}$} & Yes & $\begin{array}{l}\text { Activity (L1) or absorbed dose } \\
\text { (L3) }\end{array}$ & Optional & EANM $[19,24]$ \\
\hline $\begin{array}{l}\text { Differentiated thyroid } \\
\text { cancer }\end{array}$ & {$\left[{ }^{131} \mathrm{I}\right] \mathrm{NaI}$} & Yes & $\begin{array}{l}\text { Activity (L1) or absorbed dose } \\
\text { (L3) }\end{array}$ & Optional & $\begin{array}{l}\text { EANM [21, 25] } \\
\text { MIRD [16] }\end{array}$ \\
\hline $\begin{array}{l}\text { Neuroblastoma in } \\
\text { children }\end{array}$ & {$\left[{ }^{131} \mathrm{I}\right] \mathrm{mIBG}$} & Yes & $\begin{array}{l}\text { Activity/BW (L2)/lesion } \\
\text { absorbed dose (L3) }\end{array}$ & Advisable (L2/L3) & $\begin{array}{l}\text { EANM }[18,26] \\
\text { MIRD [16] }\end{array}$ \\
\hline \multirow[t]{3}{*}{ Neuroendocrine } & {$\left[{ }^{131} \mathrm{I}\right] \mathrm{mIBG}$} & Yes & Activity (L1) & Optional (L2) & $\begin{array}{l}\text { EANM }[18,26] \\
\text { MIRD [16] }\end{array}$ \\
\hline & $\begin{array}{l}{\left[{ }^{90} \mathrm{Y}\right] \mathrm{Y}-\mathrm{DOTATOC} \text { (and }} \\
\text { other }{ }^{177} \mathrm{Lu}-\text { or }{ }^{90} \mathrm{Y}- \\
\text { labelled SSTR ligands) }\end{array}$ & No & $\begin{array}{l}\text { Activity/BSA (L2) or absorbed } \\
\text { dose (L3) }\end{array}$ & Advisable (L2) & $\begin{array}{l}\text { EANM [27] } \\
\text { MIRD [12] }\end{array}$ \\
\hline & $\begin{array}{l}{\left[{ }^{177} \mathrm{Lu}\right] \mathrm{Lu}-\mathrm{DOTATATE}} \\
\text { (Lutathera }{ }^{\circledR} \text { ) }\end{array}$ & Yes & Activity (L1) & Optional & $\begin{array}{l}\text { EANM [27] } \\
\text { MIRD [17] }\end{array}$ \\
\hline \multirow[t]{3}{*}{ Bone pain palliation } & {$\left[{ }^{89} \mathrm{Sr}\right] \mathrm{SrCl}_{2}$} & Yes & Activity (L1) & Not feasible (L1) & \\
\hline & {$\left[{ }^{153} \mathrm{Sm}\right] \mathrm{Sm}-\mathrm{EDTMP}$} & Yes & Activity (L1) & Optional & \\
\hline & $\begin{array}{l}{ }^{223} \mathrm{Ra} \mathrm{RaCl}_{2} \\
\text { (Xofigo®) }\end{array}$ & Yes & Activity (L1) & Optional $\left({ }^{99 \mathrm{~m}} \mathrm{Tc} /{ }^{18} \mathrm{~F}\right)$ & $\begin{array}{l}\text { EANM [28] } \\
\text { MIRD [14] }\end{array}$ \\
\hline \multirow[t]{2}{*}{$\begin{array}{l}\text { Metastatic liver } \\
\text { cancer/colorectal }\end{array}$} & ${ }^{90} \mathrm{Y}$-microspheres & Yes & $\begin{array}{l}\text { Activity/BSA (L1) } \\
\text { Absorbed dose (L2/L3) }\end{array}$ & $\begin{array}{l}\text { Optional } \\
\text { advisable(L2) }\end{array}$ & EANM [29] \\
\hline & ${ }^{166}$ Ho-microspheres & Yes & Absorbed dose (L2/L3) & Required & \\
\hline $\begin{array}{l}\text { Pancreatic } \\
\text { adenocarcinoma }\end{array}$ & ${ }^{32} \mathrm{P}$-labelled microparticles & No & Absorbed dose (L3) & Required (volume) & \\
\hline $\begin{array}{l}\text { Radiation } \\
\text { synoviorthesis }\end{array}$ & $\begin{array}{l}{\left[{ }^{169} \mathrm{Er}\right] \text { Er-citrate }} \\
{\left[{ }^{90} \mathrm{Y}\right] \mathrm{Y} \text {-silicate/citrate }} \\
{\left[{ }^{186} \mathrm{Re}\right] \text { Re-sulphide }}\end{array}$ & Yes & Activity (L1) & $\begin{array}{l}\text { Not feasible } \\
\text { Optional (L1) }\end{array}$ & EANM [30] \\
\hline \multirow[t]{2}{*}{ Lymphoma } & $\begin{array}{l}{\left[{ }^{90} \mathrm{Y}\right] \mathrm{Y} \text {-ibritumomab tiuxetan }} \\
\text { (Zevalin } \AA)\end{array}$ & Yes & Activity/BW (L1) & $\begin{array}{l}\text { Not feasible } \\
\text { Optional }\left({ }^{111} \text { In }\right)\end{array}$ & $\begin{array}{l}\text { EANM [31] } \\
\text { MIRD [32] }\end{array}$ \\
\hline & $\begin{array}{l}{\left[{ }^{177} \mathrm{Lu}\right] \mathrm{Lu} \text {-lilotomab }} \\
\text { satetraxetan }\end{array}$ & No & Activity/BW (L2) & Advisable (L2) & \\
\hline $\begin{array}{l}\text { Metastatic prostate } \\
\text { cancer }\end{array}$ & {$\left[{ }^{177} \mathrm{Lu}\right] \mathrm{Lu}$-PSMA-ligands } & $\begin{array}{l}\text { No/yes after } \\
\text { MA }^{1}\end{array}$ & Activity (L1/L2) & $\begin{array}{l}\text { Advisable } \\
\quad(\mathrm{L} 2) / \text { optional }(\mathrm{L} 1)^{1}\end{array}$ & EANM [33] \\
\hline
\end{tabular}

${ }^{1}$ After marketing authorization by European regulatory authority EMA

$B W$ body weight, $B S A$ body surface area 
insert. According to this classification, all listed types of therapies except $\left[{ }^{90} \mathrm{Y}\right] \mathrm{Y}$-DOTATOC, ${ }^{32} \mathrm{P}$-labelled microparticles, $\left[{ }^{177} \mathrm{Lu}\right] \mathrm{Lu}$-lilotomab satetraxetan and $\left[{ }^{177} \mathrm{Lu}\right] \mathrm{Lu}$-PSMA-ligands are considered standardized therapies at present. Note that this classification does not apply when treatment is given according to a protocol that differs from the approved one, in which case the application is non-standardized and dosimetry should generally be included (L2). Post-therapy dose verification is not always feasible due to the emission spectrum and a diagnostic companion radiopharmaceutical is indicated.

\section{Conclusion}

Recommendations are made by the EANM to aid clinical centres in complying to the EC basic safety standards directive. The majority of nuclear medicine therapies can be considered to be standardized, when using an approved radiopharmaceutical or applying an approved device.

Three levels are defined in optimization and prescription of nuclear medicine therapy: (1) activity-based prescription and cohort-averaged dosimetry, (2) activity-based prescription and patient-specific dosimetry and (3) absorbed dose-based patient-specific prescription. In most current clinical treatments, we essentially need to guarantee that the proper activity is administered.

The authors believe that the scheme set out in this position paper will enable the centres to continue progress in the field of nuclear medicine therapy, ensure that new nuclear medicine therapies are introduced clinically and cost-effectively, stimulate research for generating further evidence and will help to optimize and standardize patient-specific therapeutic practices in nuclear medicine in Europe.

Acknowledgments The authors gratefully thank Katarina SjögreenGleisner and Søren Holm for their outstanding contributions and discussions leading to the final version of the manuscript.

Funding Open Access funding enabled and organized by Projekt DEAL.

\section{Compliance with ethical standards}

Conflict of interest MK declares that he has nothing to disclose. He is chair of the EANM Dosimetry Committee.

$\mathrm{KH}$ reports personal fees from Bayer, stock options $(<1 \%)$ from Sofie Biosciences, personal fees from SIRTEX, non-financial support from ABX, personal fees from Adacap, personal fees from Curium, personal fees from Endocyte, grants and personal fees from BTG, personal fees from IPSEN, personal fees from Siemens Healthineers, personal fees from GE Healthcare, personal fees from Amgen, personal fees from Novartis and personal fees from ymabs outside the submitted work. He is chair of the EANM Oncology Committee.

CK declares that he has nothing to disclose. He is member of the EANM Oncology Committee.
FAV has received consultancy fees from Jubilant Draximage, EISAI and Sanofi as well as speaker honoraria from Sanofi. He is member of the EANM Thyroid Committee.

$\mathrm{CH}$ declares that she has no conflict of interest. She is member of the EANM Physics Committee.

$\mathrm{RH}$ declares that he has nothing to disclose. He is member of the EANM Board.

ML has received research grants by IPSEN Pharma and Nordic Nanovector. He is member of the EANM Board.

Ethical approval This article does not contain any studies with human participants or animals performed by any of the authors.

Open Access This article is licensed under a Creative Commons Attribution 4.0 International License, which permits use, sharing, adaptation, distribution and reproduction in any medium or format, as long as you give appropriate credit to the original author(s) and the source, provide a link to the Creative Commons licence, and indicate if changes were made. The images or other third party material in this article are included in the article's Creative Commons licence, unless indicated otherwise in a credit line to the material. If material is not included in the article's Creative Commons licence and your intended use is not permitted by statutory regulation or exceeds the permitted use, you will need to obtain permission directly from the copyright holder. To view a copy of this licence, visit http://creativecommons.org/licenses/by/4.0/.

\section{References}

1. Sykiotis GP, Kalliolias GD, Papavassiliou AG. Pharmacogenetic principles in the Hippocratic writings. J Clin Pharmacol. 2005;45: 1218-20.

2. Council of the European Union. European Council Directive 2013/59/Euratom on basic safety standards for protection against the dangers arising from exposure to ionising radiation and repealing Directives 89/618/Euratom, 90/641/Euratom, 96/29/ Euratom, 97/43/Euratom and 2003/122/Euratom. Official Journal of the EU. 2014;L13:1-73.

3. Sjogreen Gleisner K, Spezi E, Solny P, Gabina PM, Cicone F, Stokke C, et al. Variations in the practice of molecular radiotherapy and implementation of dosimetry: results from a European survey. EJNMMI Phys. 2017;4:28.

4. Stokke C, Gabina PM, Solny P, Cicone F, Sandstrom M, Gleisner $\mathrm{KS}$, et al. Dosimetry-based treatment planning for molecular radiotherapy: a summary of the 2017 report from the internal dosimetry task force. EJNMMI Phys. 2017;4:27.

5. Chiesa C, Pacilio M, Strigari L, Bagni O, Maccauro M, Scopinaro G. (2 019 ) TERAPIA MEDICO NUCLEARE: OTTIMIZZAZIONE SU BASE DOSIMETRICA AI SENSI DELLA DIRETTIVA EUROPEA 2013/59/EURATOM. ASSOCIAZIONE ITALIANA DI FISICA MEDICA, ASSOCIAZIONE ITALIANA DI MEDICINA NUCLEARE

6. Chiesa C, Sjogreen Gleisner K, Flux G, Gear J, Walrand S, Bacher $\mathrm{K}$, et al. The conflict between treatment optimization and registration of radiopharmaceuticals with fixed activity posology in oncological nuclear medicine therapy. Eur J Nucl Med Mol Imaging. 2017;44:1783-6.

7. Caruana CJ, Tsapaki V, Damilakis J, Brambilla M, Martin GM, Dimov A, et al. EFOMP policy statement 16: the role and competences of medical physicists and medical physics experts under 2013/59/EURATOM. Phys Med. 2018;48:162-8.

8. Strigari L, Konijnenberg M, Chiesa C, Bardies M, Du Y, Gleisner $\mathrm{KS}$, et al. The evidence base for the use of internal dosimetry in the 
clinical practice of molecular radiotherapy. Eur J Nucl Med Mol Imaging. 2014;41:1976-88.

9. Wilke L, Andratschke N, Blanck O, Brunner TB, Combs SE, Grosu AL, et al. ICRU report 91 on prescribing, recording, and reporting of stereotactic treatments with small photon beams : statement from the DEGRO/DGMP working group stereotactic radiotherapy and radiosurgery. Strahlenther Onkol. 2019;195:193-8.

10. Lassmann M, Chiesa C, Flux G, Bardies M, Committee ED. EANM Dosimetry Committee guidance document: good practice of clinical dosimetry reporting. Eur J Nucl Med Mol Imaging. 2011;38:192-200.

11. Siegel JA, Thomas SR, Stubbs JB, Stabin MG, Hays MT, Koral $\mathrm{KF}$, et al. MIRD pamphlet no. 16: techniques for quantitative radiopharmaceutical biodistribution data acquisition and analysis for use in human radiation dose estimates. J Nucl Med. 1999;40:37S$61 \mathrm{~S}$.

12. Wessels BW, Konijnenberg MW, Dale RG, Breitz HB, Cremonesi M, Meredith RF, et al. MIRD pamphlet no. 20: the effect of model assumptions on kidney dosimetry and response-implications for radionuclide therapy. J Nucl Med. 2008;49:1884-99.

13. Bolch WE, Eckerman KF, Sgouros G, Thomas SR. MIRD pamphlet no. 21: a generalized schema for radiopharmaceutical dosimetry-standardization of nomenclature. J Nucl Med. 2009;50: 477-84.

14. Sgouros G, Roeske JC, McDevitt MR, Palm S, Allen BJ, Fisher DR, et al. MIRD pamphlet no. 22 (abridged): radiobiology and dosimetry of alpha-particle emitters for targeted radionuclide therapy. J Nucl Med. 2010;51:311-28.

15. Dewaraja YK, Frey EC, Sgouros G, Brill AB, Roberson P, Zanzonico PB, et al. MIRD pamphlet no. 23: quantitative SPECT for patient-specific 3-dimensional dosimetry in internal radionuclide therapy. J Nucl Med. 2012;53:1310-25.

16. Dewaraja YK, Ljungberg M, Green AJ, Zanzonico PB, Frey EC, Committee SM, et al. MIRD pamphlet No. 24: guidelines for quantitative ${ }^{131}$ I SPECT in dosimetry applications. J Nucl Med. 2013;54:2182-8.

17. Ljungberg M, Celler A, Konijnenberg MW, Eckerman KF, Dewaraja YK, Sjogreen-Gleisner K, et al. MIRD pamphlet no. 26: joint EANM/MIRD guidelines for quantitative ${ }^{177} \mathrm{Lu}$ SPECT applied for dosimetry of radiopharmaceutical therapy. J Nucl Med. 2016;57:151-62.

18. Gear J, Chiesa C, Lassmann M, Gabina PM, Tran-Gia J, Stokke C, et al. EANM Dosimetry Committee series on standard operational procedures for internal dosimetry for (131)I mIBG treatment of neuroendocrine tumours. EJNMMI physics. 2020;7:15.

19. Hänscheid H, Canzi C, Eschner W, Flux G, Luster M, Strigari L, et al. EANM Dosimetry Committee series on standard operational procedures for pre-therapeutic dosimetry II. Dosimetry prior to radioiodine therapy of benign thyroid diseases. Eur J Nucl Med Mol Imaging. 2013;40:1126-34.

20. Hindorf C, Glatting G, Chiesa C, Linden O, Flux G, Committee ED. EANM dosimetry committee guidelines for bone marrow and whole-body dosimetry. Eur J Nucl Med Mol Imaging. 2010;37: $1238-50$.
21. Lassmann M, Hänscheid H, Chiesa C, Hindorf C, Flux G, Luster $\mathrm{M}$, et al. EANM dosimetry committee series on standard operational procedures for pre-therapeutic dosimetry I: blood and bone marrow dosimetry in differentiated thyroid cancer therapy. Eur J Nucl Med Mol Imaging. 2008;35:1405-12.

22. Gear JI, Cox MG, Gustafsson J, Gleisner KS, Murray I, Glatting G, et al. EANM practical guidance on uncertainty analysis for molecular radiotherapy absorbed dose calculations. Eur J Nucl Med Mol Imaging. 2018;45:2456-74.

23. Huq MS, Fraass BA, Dunscombe PB, Gibbons JP Jr, Ibbott GS, Mundt AJ, et al. The report of task group 100 of the AAPM: application of risk analysis methods to radiation therapy quality management. Med Phys. 2016;43:4209.

24. Stokkel MP, Handkiewicz Junak D, Lassmann M, Dietlein M, Luster M. EANM procedure guidelines for therapy of benign thyroid disease. Eur J Nucl Med Mol Imaging. 2010;37:2218-28.

25. Luster M, Clarke SE, Dietlein M, Lassmann M, Lind P, Oyen WJ, et al. Guidelines for radioiodine therapy of differentiated thyroid cancer. Eur J Nucl Med Mol Imaging. 2008;35:1941-59.

26. Giammarile F, Chiti A, Lassmann M, Brans B, Eanm FG. EANM procedure guidelines for 131I-meta-iodobenzylguanidine (131ImIBG) therapy. Eur J Nucl Med Mol Imaging. 2008;35:1039-47.

27. Bodei L, Mueller-Brand J, Baum RP, Pavel ME, Horsch D, O'Dorisio MS, et al. The joint IAEA, EANM, and SNMMI practical guidance on peptide receptor radionuclide therapy (PRRNT) in neuroendocrine tumours. Eur J Nucl Med Mol Imaging. 2013;40: 800-16.

28. Poeppel TD, Handkiewicz-Junak D, Andreeff M, Becherer A, Bockisch A, Fricke E, et al. EANM guideline for radionuclide therapy with radium-223 of metastatic castration-resistant prostate cancer. Eur J Nucl Med Mol Imaging. 2018;45:824-45.

29. Giammarile F, Bodei L, Chiesa C, Flux G, Forrer F, KraeberBodere $\mathrm{F}$, et al. EANM procedure guideline for the treatment of liver cancer and liver metastases with intra-arterial radioactive compounds. Eur J Nucl Med Mol Imaging. 2011;38:1393-406.

30. Clunie G, Fischer M. Eanm EANM procedure guidelines for radiosynovectomy. Eur J Nucl Med Mol Imaging. 2003;30: BP12-6.

31. Tennvall J, Fischer M, Bischof Delaloye A, Bombardieri E, Bodei $\mathrm{L}$, Giammarile F, et al. EANM procedure guideline for radioimmunotherapy for B-cell lymphoma with ${ }^{90} \mathrm{Y}$-radiolabelled ibritumomab tiuxetan (Zevalin). Eur J Nucl Med Mol Imaging. 2007;34:616-22.

32. Fisher DR, Shen S, Meredith RF. MIRD dose estimate report no. 20: radiation absorbed-dose estimates for ${ }^{111} \mathrm{In}$ - and ${ }^{90} \mathrm{Y}$ ibritumomab tiuxetan. J Nucl Med. 2009;50:644-52.

33. Kratochwil C, Fendler WP, Eiber M, Baum R, Bozkurt MF, Czernin J, et al. EANM procedure guidelines for radionuclide therapy with ${ }^{177}$ Lu-labelled PSMA-ligands $\left({ }^{177} \mathrm{Lu}\right.$-PSMA-RLT) $)$ Eur J Nucl Med Mol Imaging. 2019;46:2536-44.

Publisher's note Springer Nature remains neutral with regard to jurisdictional claims in published maps and institutional affiliations. 